\title{
Recordando Paulo Bettencourt
}

\section{In Memorium: Paulo Bettencourt}

\author{
António Ferreira (https://orcid.org/0000-0002-1974-6684) \\ Professor Auxiliar Convidado \\ Faculdade de Medicina Universidade do Porto, Departamento de Medicina
}

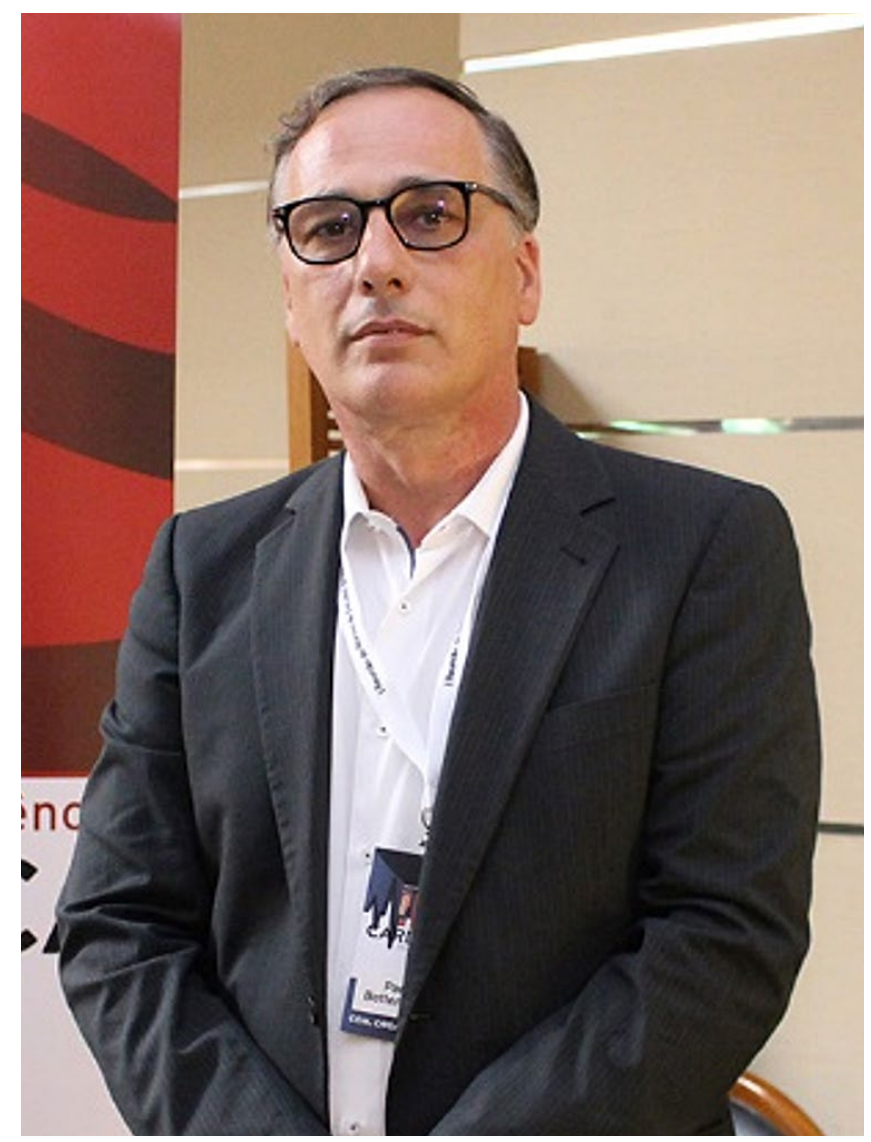

Paulo Miguel Bettencourt Sardinha e Pontes Fernando nasceu na freguesia de Santo Ildefonso, no Porto, a 12 de março de 1965, segundo filho de João Fernando, advogado e Margarida Sardinha, professora. Passou os primeiros tempos da sua vida em Vila Nova de Cerveira, em cujo cartório o pai trabalhava. Pouco tempo depois, a família mudou-se para a Póvoa de Varzim, onde assentou arraiais. Aí viveu, estudou, na Escola Secundária de Eça de Queiróz, criou amizades e laços afetivos que perduraram para a vida. Inteligente e estudioso, uma característica que manteve até ao dia da sua morte, facilmente conseguiu ingressar na mais concorrida escola médica do tempo - a Faculdade de Medicina da Universidade do Porto. Ainda enquanto aluno, foi monitor e, depois, assistente convidado de Anatomia da mesma faculdade.

DOI:10.24950/rspmi.obituario.4.2021
Concluiu os estudos médicos em 1989 e, dois anos depois, o Internato Geral no Hospital de São João. No mesmo hospital, no Serviço de Medicina 3, sob orientação da Dra. Rosário Capucho, tornou-se especialista de Medicina Interna, em 1996. No último ano do internato, integrou a Unidade de Investigação e Desenvolvimento Cardiovascular do Porto (Unidade n 51/94 da FCT), onde dirigiu a "Clinical Research in Cardiovascular Diseases".

Doutorou-se em Medicina em 2001, na Faculdade de Medicina da Universidade do Porto, tendo como orientador o Professor Doutor Mário Cerqueira Gomes. A tese, pioneira, abordou o valor dos peptídeos natriuréticos na insuficiência cardíaca, tema no qual se transformou em investigador de grande prestígio internacional.

Publicou mais de 300 artigos científicos em revistas indexadas, com "peer review" e considerável impacto internacional. Com 6328 citações, atingiu um índice H de 41, uma marca extraordinária na área da investigação clínica. Uma das suas publicações, na Circulation, foi citada, até ao momento, 831 vezes, catorze foram citadas mais de 100 vezes e trinta e cinco mais de 50 vezes.

Foi autor de mais de 900 comunicações em reuniões científicas nacionais e internacionais e palestrante convidado de mais de vinte reuniões científicas internacionais, realizadas em Portugal e no estrangeiro, nomeadamente em Berlim, Salvador da Bahia, Creta, Dresden, Barcelona, Vancouver, Jacarta, Chicago, Madrid, Saragoça, Oviedo, Valência e Shenzhen.

Colaborou em projetos de investigação com várias instituições estrangeiras, nomeadamente a Universidade de Zaragoza, o Amesterdam Academic Center, a Harvard University/ Massachusetts General Hospital.

Foi revisor de muitas revistas nacionais e internacionais, entre as quais: American Heart Journal; American Journal of Cardiology; American Journal of Medicine; Canadian Journal of Cardiology; Cardiology; Circulation; Circulation Heart Failure; Clinical Chemistry and Laboratory Medicine; European Heart Journal; European Journal of Heart Failure; Expert Opinion on Biological Therapies; Journal of the American College of Cardiology; Journal of the American College of Cardiology - Heart Failure; Journal of General Internal Medicine; Heart; International Journal of Cardiology, Italian Journal Cardiology; Revista Portuguesa de Cardiologia, Arquivos de Medicina.

Internista de grande notoriedade, autoridade e influência, foi assistente graduado sénior e diretor do Serviço de 
Medicina Interna do Centro Hospitalar de São João durante dez anos, presidente da Comissão de Farmácia e Terapêutica, adjunto da Direção Clínica e membro de várias comissões e grupos de trabalho.

Foi Professor Associado com Agregação da Faculdade de Medicina da Universidade do Porto, regente da unidade curricular de Semiótica, posteriormente Professor Catedrático Convidado, membro do Conselho Executivo, membro do Conselho Científico do Curso Doutoral em Ciências Cardiovasculares, membro do Conselho Pedagógico e membro da Comissão Científica do Curso de Mestrado Integrado.

Orientou 12 teses de doutoramento e participou em vinte júris de doutoramento (seis como arguente) em várias universidades portuguesas, espanholas (como presidente do júri) e holandesas.

Foi avaliador da Fundação para a Ciência e Tecnologia na área das Ciências da Saúde, consultor do Ministério da Saúde Holandês para o programa de financiamento de projetos de investigação clínica e da Agence Nationale pour la Recherche.

Foi, ainda, perito do Infarmed, membro da Comissão de Boas Práticas Clínicas da Direção-Geral de Saúde/Ordem dos Médicos, Presidente da Comissão Científica da Administração Regional de Saúde do Norte, Coordenador do Núcleo de Estudos de Insuficiência Cardíaca da Sociedade Portuguesa de Medicina Interna, perito da Comissão para a Organização de Cuidados de Saúde a Doentes com Insuficiência Cardíaca do Ministério da Saúde.

Em 2016 transferiu-se para o Hospital da CUF Porto, para coordenar a Área de Medicina Interna.

Faleceu a 4 de setembro de 2021, com 56 anos.

As suas excecionais qualidades humanas, a entrega e dedicação aos seus doentes e o seu altruísmo, a sua afabilidade e cortesia, juntamente com a sua extraordinária competência e cultura médicas, transformaram-no num médico respeitado e amado por todos, doentes e colegas. $O$ seu desaparecimento do convívio dos vivos deixa uma profunda consternação na sociedade e nos mundos académico, científico e médico.

\section{Responsabilidades Éticas}

Conflitos de Interesse: Os autores declaram a inexistência de conflitos de interesse na realização do presente trabalho.

Fontes de Financiamento: Não existiram fontes externas de financiamento para a realização deste artigo.

\section{Ethical Disclosures}

Conflicts of interest: The authors have no conflicts of interest to declare. Financing Support: This work has not received any contribution, grant or scholarship

(c) Autor (es) (ou seu (s) empregador (es)) e Revista SPMI 2021. Reutilização permitida de acordo com CC BY-NC. Nenhuma reutilização comercial. (C) Author(s) (or their employer(s)) and SPMl Journal 2021. Re-use permitted under CC BY-NC. No commercial re-use.

\section{Correspondence / Correspondência:}

António Ferreira - aloboferreira@gmail.com

Professor Auxiliar Convidado, Departamento de Medicina

Faculdade de Medicina Universidade do Porto

Alameda Prof. Hernâni Monteiro, 4200-319 Porto

Received / Recebido: 15/09/2021

Accepted / Aceite: 15/09/2021

Publicado / Published: 21/12/202 